\title{
Communication \\ A Comparison of Drill and Broadcast Planting Methods for Biomass Production of Two Legume Cover Crops
}

\author{
Ricardo St Aime ${ }^{1}$, Enoch Noh ${ }^{1}$,, William C. Bridges, $\mathrm{Jr}^{2}{ }^{2}$ and Sruthi Narayanan ${ }^{1, *(\mathbb{C}}$ \\ 1 Department of Plant and Environmental Sciences, Clemson University, Clemson, SC 29634, USA; \\ rstaime@g.clemson.edu (R.S.A.); enoh@g.clemson.edu (E.N.) \\ 2 School of Mathematical and Statistical Sciences, Clemson University, Clemson, SC 29634, USA; \\ WBRDGS@clemson.edu \\ * Correspondence: skutty@clemson.edu
}

Citation: St Aime, R.; Noh, E.; Bridges, W.C., Jr.; Narayanan, S. A Comparison of Drill and Broadcast Planting Methods for Biomass Production of Two Legume Cover Crops. Agronomy 2022, 12, 79. https://doi.org/10.3390/ agronomy12010079

Academic Editor: Marisol Berti

Received: 3 December 2021

Accepted: 27 December 2021

Published: 30 December 2021

Publisher's Note: MDPI stays neutral with regard to jurisdictional claims in published maps and institutional affiliations.

Copyright: (C) 2021 by the authors. Licensee MDPI, Basel, Switzerland. This article is an open access article distributed under the terms and conditions of the Creative Commons Attribution (CC BY) license (https:// creativecommons.org/licenses/by/ $4.0 /)$.

\begin{abstract}
The effects of drill and broadcast planting methods on cover crop biomass production depend on various environmental and operational factors. We investigated whether drilling and broadcasting result in different amounts of biomass production by crimson clover (Trifolium incarnatum L.) and hairy vetch (Vicia villosa Roth) in the upstate of South Carolina, and results vary when seeding rates are increased by $50 \%$ from the standard value $\left(22.4 \mathrm{~kg} \mathrm{ha}^{-1}\right)$. Field trials were conducted during the fall-winter of 2019-2020 (season one) and 2020-2021 (season two) at the Piedmont Research and Education Center in Pendleton, SC, USA. Cover crop (hairy vetch, crimson clover), planting method (broadcast, drill), and seeding rate (standard, high) treatments were arranged as a $2 \times 2 \times 2$ factorial in both years. Aboveground biomass was measured after 22.5 weeks from planting. At standard seeding rates, crimson clover produced a higher biomass when drilled, rather than broadcasted, whereas biomass production did not vary for hairy vetch. Even with $50 \%$ higher seeding rates, broadcasting did not always produce the same biomass as that of drilling for crimson clover. Our results suggest that the advantage of drilling over broadcasting depends upon the cover crop species, as crimson clover responds well to drilling, whereas hairy vetch does not.
\end{abstract}

Keywords: cover crops; planting method; seeding rate; biomass

\section{Introduction}

Planting strategies that improve cover crop stand establishment and biomass production are critical to ensure cover crop benefits, such as weed suppression, nutrient scavenging, and erosion control [1]. Drilling and broadcasting are common planting methods for cover crops [2,3]. Drilling has been the dominant planting practice in mechanized farming systems for more than a century [4]. A recent survey in Nebraska reported that more than $65 \%$ farmers preferred drilling as the cover crop establishment method after harvesting a cash crop [5].

A no-till drill or conventional drill can be used to drill cover crops. Broadcasting of cover crop seeds is usually accomplished through centrifugal spreaders that hurl seeds horizontally onto the soil's surface or through implements attached to tractors or aircraft that drop seeds vertically onto the soil [1]. Aerial or ground broadcast methods are sometimes followed by a tillage operation to incorporate the seed into the soil. Farmers skip the incorporation operation when soil is too wet to get machinery into the field or when cover crops are inter-seeded with a standing cash crop [6].

The effects of broadcast- and drill-planting methods on cover crop stand establishment and biomass production depend on various factors, such as seeding rate, soil and seedbed conditions, sowing implement, climate, and incorporation of seed into the soil [1,2]. Thus, it may not be appropriate to conclude whether one method is universally superior over the other. Some farmers prefer to broadcast cover crops, considering the reduced cost associated with broadcasting and its ability to cover large acreage in a relatively short 
period of time. The 2021 Iowa Farm Custom Survey reported that the average cost for drilling cover crop seeds was $\$ 16.15$ per acre, whereas aerial seeding of cover crops resulted in $\$ 12.40$ per acre and broadcasting grass seeds with a tractor or ATV resulted in $\$ 11.35$ and $\$ 12.50$ per acre, respectively [7]. Additionally, broadcasting may allow for earlier planting than drilling because cover crops can be broadcasted into a standing crop pre-harvest. This is especially relevant in the southeast, where long growing seasons for summer cash crops often delay planting of fall cover crops. However, the success of broadcasting depends on adequate and timely rainfall [2]. Lack of rainfall can result in low emergence [2], and other factors such as poor seed-to-soil contact, as well as seed predation, also contribute to uneven stands $[1,8]$. To address low emergence, $\geq 50 \%$ increases in seeding rates are often recommended for broadcasting, rather than drilling [1]. However, it appears that any advantage of higher seeding rates is region-specific, especially under rain-fed production conditions, as adequate soil moisture should be available to support an increased plant population [2,8-11]. Our study was motivated by the need to find effective cover crop planting strategies for the southeastern U.S. The objective of this study was to evaluate biomass production of two legume cover crops: crimson clover (Trifolium incarnatum L.) and hairy vetch (Vicia villosa Roth), under two different planting methods (broadcasting and drilling) and seeding rates (standard and high).

\section{Materials and Methods}

The cover crops evaluated in this study, crimson clover and hairy vetch, are common winter cover crops in the southeastern U.S. With its rapid and robust growth, crimson clover serves as a weed-suppressing green manure and staple forage crop and provides early spring nitrogen for full-season crops [12]. Hairy vetch often surpasses most legumes, including crimson clover, for biomass production and nitrogen contribution [12].

Field trials were conducted during the fall-winter of 2019-2020 (season one) and 2020-2021 (season two) at the Piedmont Research and Education Center in Pendleton, SC $\left(34^{\circ} 37^{\prime} 30.1^{\prime \prime} \mathrm{N},-82^{\circ} 44^{\prime} 13.9^{\prime \prime} \mathrm{W}\right.$, altitude $\left.253 \mathrm{~m}\right)$. The soil series at the study site is Cecil sandy loam (clayey, kaolinitic, thermic typic Kanhapludults). Annually this region receives an average precipitation of $138 \mathrm{~cm}$ with temperatures typically ranging from $2{ }^{\circ} \mathrm{C}$ to $32{ }^{\circ} \mathrm{C}$ and rarely falling below $-5{ }^{\circ} \mathrm{C}$ or above $36^{\circ} \mathrm{C}$ [13]. Prior to the study in fall 2019, the cropping sequence was a two-year soybean (Glycine max (L.) Merr.) -corn (Zea mays L.) rotation in which either oat (Avena sativa L.) or fallow was added in the fall, beginning in 2016.

In both years, land preparation included a deep tillage with a chisel plow (Model \# 156 D75242, Athens plow company, Athens, TN, USA) four days before cover crop planting, and harrowing with a field cultivator (Model Perfecta II \#3265, Unverferth Manufacturing, Kalida, $\mathrm{OH}, \mathrm{USA}$ ) one day before cover crop planting. Soil samples were collected on 25 October 2019 (season one) and 15 October 2020 (season two) to conduct soil analysis before planting in each season. The results of the soil analysis are presented in Table 1.

The experimental design was a randomized complete block design (RCBD) with five replications. Treatments were arranged as $2 \times 2 \times 2$ factorial and included cover crop species (hairy vetch, crimson clover), planting methods (broadcast, drill) and seeding rates (standard, high). Plots were 6.1 by $3 \mathrm{~m}$ in size in both seasons. A $2 \mathrm{~m}$ alley separated the individual plots. The field trials were conducted under rain-fed conditions in both seasons.

Dixie crimson clover and AU Merit hairy vetch were planted via drilling or broadcasting on 29 October 2019 in season one and 20 November 2020 in season two. Planting was delayed in season two because a lack of moisture in the field prevented planting in October. Good quality seeds with more than $80 \%$ germination were used in both seasons for both cover crops. Seeds were not inoculated. Drilling was accomplished using a four-row conedrill (Allan machine company, Nevada, IA, USA) with a $0.17 \mathrm{~m}$ row spacing and a $\sim 2.5 \mathrm{~cm}$ seeding depth. Broadcasting was accomplished using a Sta-Green 32-lb broadcast spreader (Model \#75260, Parker fertilizer company, Sylacauga, AL, USA). The broadcast treatment did not involve the incorporation of seeds into the soil with any tillage implement. 
Each cover crop under each planting method was sown with two different seeding rates: standard and 50\% higher. Standard and high seeding rates were 22.4 and $33.6 \mathrm{~kg} \mathrm{ha}^{-1}$, respectively, for both cover crops. The 'standard' seeding rate involved 1129 and 82 pure live seeds $\mathrm{m}^{-2}$ for crimson clover and hairy vetch, respectively and the 'high' seeding rate involved 1694 and 123 pure live seeds $\mathrm{m}^{-2}$ for crimson clover and hairy vetch, respectively.

Table 1. Results of soil analysis conducted before planting in season one and season two at the Clemson University Agricultural Service Laboratory, Clemson, SC, USA. The remarks: medium and sufficient indicate soil nutrient status provided in the soil analysis results.

\begin{tabular}{ccc}
\hline Soil Parameter/Nutrients & Season One & Season Two \\
\hline Soil $\mathrm{pH}$ & 6.6 & 6.0 \\
Phosphorus $\left(\mathrm{Kg} \mathrm{ha}^{-1}\right)$ & 41 (Medium) & 45 (Medium) \\
Potassium $\left(\mathrm{Kg} \mathrm{ha}^{-1}\right)$ & 154 (Medium) & 108 (Medium) \\
Calcium $\left(\mathrm{Kg} \mathrm{ha}^{-1}\right)$ & 1293 (Sufficient) & 788 (Medium) \\
Magnesium $\left(\mathrm{Kg} \mathrm{ha}^{-1}\right)$ & 346 (Sufficient) & 136 (Sufficient) \\
Zinc $\left(\mathrm{Kg} \mathrm{ha}^{-1}\right)$ & 3.6 (Sufficient) & 5.5 (Sufficient) \\
Manganese $\left(\mathrm{Kg} \mathrm{ha}^{-1}\right)$ & 34 (Sufficient) & 19 (Sufficient) \\
Boron $\left(\mathrm{Kg} \mathrm{ha}^{-1}\right)$ & 0.4 (Sufficient) & 0.5 (Sufficient) \\
Copper $\left(\mathrm{Kg} \mathrm{ha}^{-1}\right)$ & 0.56 & 1.01 \\
Sodium $\left(\mathrm{Kg} \mathrm{ha}^{-1}\right)$ & 9 & 21.3 \\
Nitrate nitrogen $(\mathrm{ppm})$ & 11 & N/A \\
Organic matter (\%) & 4.1 & N/A \\
\hline
\end{tabular}

${ }^{1}$ Not measured.

In season two, the plant population was measured by counting the number of seedlings within a $0.25-\mathrm{m}^{2}$ quadrat, randomly placed at two locations within each plot at 61 days after planting (DAP) [14]. When placing the quadrat, one meter was left on each side to avoid edge effects. Aboveground biomass was measured at $160 \mathrm{DAP}$ in season one and 159 DAP in season two. Crimson clover was at the flowering stage and hairy vetch at the vegetative stage at the time of biomass harvest in season 1 . In season two, both cover crops were at flowering stage at the time of biomass harvest. Aboveground biomass was harvested from a $7.4 \mathrm{~m}^{2}$ area in each plot by a forage harvester (Carter manufacturing Co., Inc, Brookston, IN, USA) that provided the fresh weight of harvested biomass. The fresh weights of biomass samples were converted to their dry weight by multiplying the fresh weight with the dry matter percentage [15-17].

\section{Statistical Analysis}

Analysis of variance was performed with the GLIMMIX procedure in SAS (version 9.4, SAS Institute, Cary, NC, USA). The planting method, seeding rate, cover crops, and their interactions were considered as fixed effects and replication as a random effect. Separation of means was performed using the Fisher's least significant difference (LSD) test in the GLIMMIX procedure. The probability threshold level $(\alpha)$ for statistical significance was set at 0.05 .

\section{Results and Discussion}

In the fall-winter of 2019-2020 (season one), the experimental site received higher precipitation than what is normal for the location, based on historical precipitation data (Figure 1a). On the other hand, in the fall-winter of 2020-2021 (season two), precipitation was slightly lower than what is normal for the location (Figure 1a). Total precipitation was $76 \mathrm{~cm}$ in season one and $54 \mathrm{~cm}$ in season two. In the first three weeks after the planting of cover crops, $9.3 \mathrm{~cm}$ of precipitation was received in season one, while only $5.7 \mathrm{~cm}$ of precipitation was received in season two. The daily average air temperatures ranged from -1.9 to $20.6{ }^{\circ} \mathrm{C}$ with an average of $9.3^{\circ} \mathrm{C}$ in season one and from -4.2 to $27.2{ }^{\circ} \mathrm{C}$ with an average of $8.6^{\circ} \mathrm{C}$ in season two. In both seasons, daily average temperatures were higher than the 30 year normals on most days (Figure $1 b$ ). 


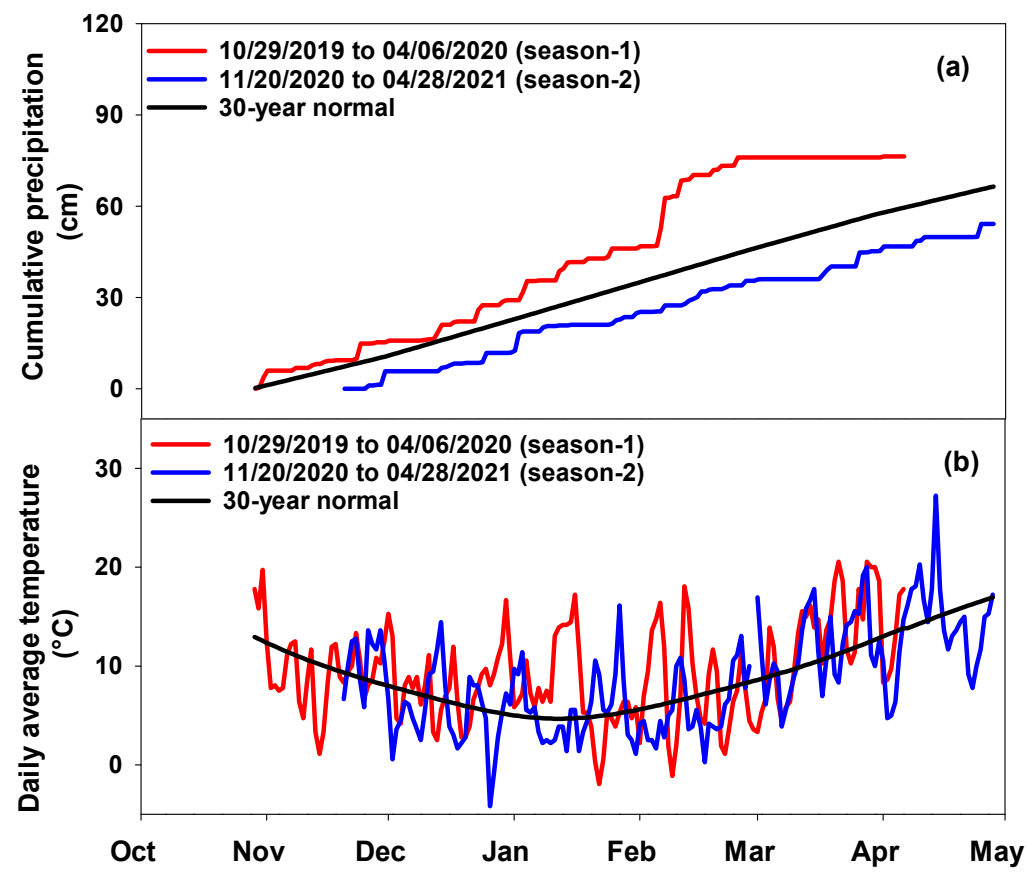

Figure 1. Cumulative precipitation (a) and daily average temperatures (b) from planting through the harvest of cover crops in comparison with the 30 year normal data. Cumulative precipitation normals for the $160 \mathrm{~d}$ period in both seasons were calculated from the daily precipitation normal for a period of 30 years from 1991 to 2020. Precipitation and temperature data were obtained from the South Carolina State Climatology Office, a division within the South Carolina Department of Natural Resources.

In this study, each cover crop was sown at a standard seeding rate $\left(22.4 \mathrm{~kg} \mathrm{ha}^{-1}\right)$ and a high seeding rate $\left(33.6 \mathrm{~kg} \mathrm{ha}^{-1}\right)$. The recommended range of seeding rates for crimson clover is 17 to $20 \mathrm{~kg} \mathrm{ha}^{-1}$ for drilling and 25 to $34 \mathrm{~kg} \mathrm{ha}^{-1}$ for broadcasting [12]. For hairy vetch, it is 17 to $22 \mathrm{~kg} \mathrm{ha}^{-1}$ for drilling and 28 to $34 \mathrm{~kg} \mathrm{ha}^{-1}$ for broadcasting [12]. As a comparison of seed size between the two cover crops, Dixie crimson clover had about 573,000 seeds $\mathrm{kg}^{-1}$, while AU Merit hairy vetch had about 44,100 seeds $\mathrm{kg}^{-1}$ (information provided by the seed vendors).

The main effect of the seeding rate was not significant on biomass production in both seasons ( $p$-value, 0.485 in season one and 0.722 in season two). Our result is supported by previous reports that when seeding rates were increased, even when they increased the stand counts, they did not improve biomass of drilled or broadcasted cover crops at or after the onset of reproductive stage $[10,11,18]$. It is likely that the available water and nutrients in our study site supported cover crops only at lower seeding rates. Based on the 2021 pricing of five major seed sources in South Carolina (Adams-Briscoe, BWI, Dillon Seeds, Little Mill Seeds, and Farm \& Turf), a high seeding rate increases the seed cost by $\$ 31$ to $\$ 70 \mathrm{ha}^{-1}$ for crimson clover and $\$ 37$ to $\$ 91 \mathrm{ha}^{-1}$ for hairy vetch. If increasing the seeding rate does not increase biomass production, farmers do not have to buy extra quantities of seeds in order to use a higher seeding rate, which will help them save money on seed prices.

In our study, the main effects of the cover crop ( $p$-value, 0.006 in season one and 0.0004 in season two) and planting method ( $p$-value, 0.002 in season one and 0.016 in season two) used were significant on biomass production in both seasons. The effects of the planting method-by-cover crop interaction was significant on biomass production in season one ( $p$-value, 0.008 for season one and 0.726 for season two). In both seasons, crimson clover produced a higher biomass when drilled, rather than broadcasted, under standard seeding rates (Table 2), suggesting that drilling is a better planting method for crimson clover in terms of biomass production in upstate South Carolina. In season one, even with a 50\% 
higher seeding rate, broadcasting resulted in less biomass production than drilling for crimson clover (Table 2). However, in season two, broadcasting with high seeding rates resulted in the same amount of biomass as drilling at standard or high seeding rates for crimson clover. This may be because drilling produced a smaller amount of biomass in season two than in season one for this species, the reason for which is hard to determine based on the available information. It might be possible that the delayed planting date in season two, which was outside the optimal window for crimson clover in this region, affected the biomass production potential of drilling for this species.

Table 2. Biomass production and plant population of crimson clover and hairy vetch under two different planting methods (broadcasting and drilling) and seeding rates [standard [12], $22.4 \mathrm{~kg} \mathrm{ha}^{-1}$ and $50 \%$ higher, $\left.33.6 \mathrm{~kg} \mathrm{ha}^{-1}\right]$. Plant population was measured at 61 days after planting.

\begin{tabular}{|c|c|c|c|c|c|}
\hline \multirow[t]{2}{*}{ Cover Crop } & \multirow[t]{2}{*}{ Seeding Rate } & \multirow[t]{2}{*}{ Planting Method } & \multicolumn{2}{|c|}{$\begin{array}{l}\text { Biomass }^{1} \\
\left(\mathrm{Kg} \mathrm{ha}^{-1}\right)\end{array}$} & \multirow{2}{*}{$\begin{array}{c}\text { Plant Population } \\
1 \text { (Plants } \mathrm{m}^{-2} \text { ) }\end{array}$} \\
\hline & & & 2019-2020 & $2020-2021$ & \\
\hline \multirow{4}{*}{ Crimson clover } & Standard & Drilling & $3186 \pm 204^{\mathrm{A}}$ & $2556 \pm 81^{A}$ & $170 \pm 12^{\mathrm{AB}}$ \\
\hline & Standard & Broadcasting & $1498 \pm 244^{B}$ & $1998 \pm 273^{B}$ & $146 \pm 12^{\mathrm{B}}$ \\
\hline & High & Drilling & $3278 \pm 621^{A}$ & $2549 \pm 376^{\mathrm{A}}$ & $202 \pm 12^{A}$ \\
\hline & High & Broadcasting & $1855 \pm 229^{B}$ & $2369 \pm 319 \mathrm{AB}$ & $166 \pm 12 \mathrm{AB}$ \\
\hline \multirow{4}{*}{ Hairy vetch } & Standard & Drilling & $1869 \pm 431^{\mathrm{a}}$ & $1914 \pm 307^{a b}$ & $52 \pm 4^{b c}$ \\
\hline & Standard & Broadcasting & $1530 \pm 76^{\mathrm{a}}$ & $1870 \pm 322 \mathrm{ab}$ & $46 \pm 4^{c}$ \\
\hline & High & Drilling & $1787 \pm 23^{a}$ & $2073 \pm 218^{a}$ & $70 \pm 4^{a}$ \\
\hline & High & Broadcasting & $1714 \pm 356^{\mathrm{a}}$ & $1549 \pm 231^{b}$ & $63 \pm 4^{a b}$ \\
\hline \multicolumn{6}{|c|}{ Main effects of planting method across seeding rates } \\
\hline \multirow{2}{*}{ Crimson clover } & \multirow{2}{*}{$\mathrm{N} / \mathrm{A}$} & Drilling & $3232 \pm 173^{\mathrm{A}}$ & $2560 \pm 247^{\mathrm{A}}$ & $186 \pm 9^{\mathrm{A}}$ \\
\hline & & Broadcasting & $1676 \pm 212^{B}$ & $2184 \pm 243^{\mathrm{B}}$ & $156 \pm 9^{B}$ \\
\hline \multirow{2}{*}{ Hairy vetch } & \multirow{2}{*}{$\mathrm{N} / \mathrm{A}$} & Drilling & $1829 \pm 172^{a}$ & $1993 \pm 99^{a}$ & $61 \pm 3^{a}$ \\
\hline & & Broadcasting & $1622 \pm 172^{\mathrm{a}}$ & $1709 \pm 99^{a}$ & $55 \pm 3^{a}$ \\
\hline
\end{tabular}

${ }^{1}$ Values shown are means \pm standard deviations. Means with different letters are significantly different according to Fisher's least significant difference (LSD) test at $\alpha=0.05$. Uppercase letters followed by means compare treatments applied to crimson clover, whereas lowercase letters compare treatments applied to hairy vetch.

For hairy vetch, drilling and broadcasting resulted in the same amount of biomass production in season one under standard or high seeding rates (Table 2). In season two, similar results were observed under the standard seeding rate. Under the high seeding rate, hairy vetch produced a higher biomass when drilled, rather than broadcasted, in season two. These results suggest that hairy vetch does not necessarily produce higher biomass if drilled, compared to broadcasted.

The planting cost of crimson clover and hairy vetch varies according to planting method. Smith et al. [19] reported a 19-31\% increase in planting cost when crimson clover was drilled, compared to broadcasted, in Arkansas. A farmer-led research group in Iowa found that drilling is at least $9 \%$ more expensive than other planting methods for hairy vetch [20]. Since drilling increases the biomass production of crimson clover, but not of hairy vetch, the additional planting cost of drilling may still be justifiable for crimson clover, but not for hairy vetch, in upstate South Carolina.

The present results were obtained when cover crops were planted after conventional tillage operations. Future studies are required to verify the results under no-till conditions. The poor seed-to-soil contact that might arise under no-till conditions, especially under the broadcast planting method and for small-seeded species like crimson clover, may add an extra factor that influences biomass production under different planting methods and seeding rates. 


\section{Conclusions}

Our results indicate that the advantage of drilling over broadcasting depends upon the cover crop species and seeding rates. In upstate South Carolina, at normal (standard) seeding rates, crimson clover responds well to drilling in terms of biomass production, whereas hairy vetch does not. For crimson clover, even with higher seeding rates, broadcasting may not necessarily produce the same amount of biomass as that of drilling. Thus, farmers will benefit from spending money, time, and effort in planting crimson clover via drilling. For hairy vetch, which does not respond well to drilling, farmers in our location may take advantage of the relatively simpler and less expensive planting method of broadcasting.

Author Contributions: Conceptualization, S.N.; methodology, R.S.A. and S.N.; validation, R.S.A. and S.N.; formal analysis, R.S.A., S.N. and W.C.B.J.; investigation, R.S.A. and E.N.; resources, S.N.; data curation, R.S.A.; writing —original draft preparation, R.S.A.; writing—review and editing, R.S.A., S.N. and E.N.; visualization, R.S.A. and S.N.; supervision, S.N.; project administration, S.N.; funding acquisition, S.N. All authors have read and agreed to the published version of the manuscript.

Funding: This research was funded by the Clemson University Support for Early Exploration and Development (CU SEED) Grant \#1502439. This work was also supported by the USDA National Institute of Food and Agriculture, Hatch/Multi-State project 1023286 and the Southern Cover Crop Council.

Institutional Review Board Statement: Not applicable.

Data Availability Statement: Raw data are available upon request to Sruthi Narayanan. Data have not been archived in a repository.

Acknowledgments: We thank the Piedmont Research and Education Center field crew for help with field operations and Victoria Burgess and Vince Cantrell for help with data collection. We thank Sarah Seehaver (North Carolina State University) for sending us the cover crop seeds. This publication is Technical Contribution No.7001 of the Clemson University Experiment Station.

Conflicts of Interest: The authors declare no conflict of interest. The funders had no role in the design of the study; in the collection, analyses, or interpretation of data; in the writing of the manuscript, or in the decision to publish the results.

\section{References}

1. Brennan, E.B.; Leap, J.E. A comparison of drill and broadcast methods for establishing cover crops on beds. HortScience 2014, 49, 441-447. [CrossRef]

2. Fisher, K.A.; Momen, B.; Kratochvil, R.J. Is broadcasting seed an effective winter cover crop planting method? Agron. J. 2011, 103, 472-478. [CrossRef]

3. Van Horn, M.; Brennan, E.B.; Daugovish, O.; Mitchell, J. Cover crop management. In Cover Cropping for Vegetable Production. A Grower's Handbook; Smith, R.F., Bugg, R.L., Daugovish, O., Gaskell, M., Van Horn, M., Eds.; University of California: Oakland, CA, USA, 2011; pp. 71-78.

4. Heege, H.J. Seeding methods performance for cereals, rape, and beans. Trans. ASAE (USA) 1993, 36, 653-661. [CrossRef]

5. Oliveira, M.C.; Butts, L.; Werle, R. Assessment of cover crop management strategies in Nebraska, US. Agriculture 2019, 9, 124. [CrossRef]

6. USDA Cover Crop Technical Note No. 16. South Dakota Technical Guide Section I-Technical Notes-Agronomy. 2021 Available online: file:// /C:/Users/skutty/AppData/Local/Temp/SD_Cover_Crop_Tech_Note_16_July2021.pdf (accessed on 2 December 2021).

7. Plastina, A.; Johanns, A.; Gleisner, A.; Qualman, A. 2021 Iowa Farm Custom Rate Survey; File A3-10; Iowa State University Extension and Outreach: Ames, IA, USA, 2021.

8. Wilson, M.L.; Baker, J.M.; Allan, D.L. Factors affecting successful establishment of aerially seeded winter rye. Agron. J. 2013, 105, 1868-1877. [CrossRef]

9. Mirsky, S.B.; Ackroyd, V.J.; Cordeau, S.; Curran, W.S.; Hashemi, M.; Reberg-Horton, S.C.; Ryan, M.R.; Spargo, J.T. Hairy vetch biomass across the eastern United States: Effects of latitude, seeding rate and date, and termination timing. Agron. J. 2017, 109, 1510-1519. [CrossRef]

10. Haramoto, E.R. Species, seeding rate, and planting method influence cover crop services prior to soybean. Agron. J. 2019, 111, 1068-1078. [CrossRef]

11. Koehler-Cole, K.; Elmore, R.W. Seeding rates and productivity of broadcast interseeded cover crops. Agronomy 2020, 10, 1723. [CrossRef] 
12. Clark, A. Managing Cover Crops Profitably, 3rd ed.; Sustainable Agriculture Research and Education (SARE). Handbook Series Book 9; University of Maryland: College Park, MD, USA, 2012.

13. National Oceanic \& Atmospheric Administration. U.S. Climate Normal Quick Access. 2021. Available online: https://www.ncei. noaa.gov/access/us-climate-normals / (accessed on 2 December 2021).

14. Murrell, E.G.; Schipanski, M.E.; Finney, D.M.; Hunter, M.C.; Burgess, M.; LaChance, J.C.; Kaye, J.P. Achieving diverse cover crop mixtures: Effects of planting date and seeding rate. Agron. J. 2017, 109, 259-271. [CrossRef]

15. Rajcan, I.; Tollenaar, M. Source:sink ratio and leaf senescence in maize: I. Dry matter accumulation and partitioning during grain filling. Field Crops Res. 1999, 60, 245-253. [CrossRef]

16. Pordesimo, L.O.; Edens, W.C.; Sokhansanj, S. Distribution of aboveground biomass in corn stover. Biomass Bioenergy 2004, 26, 337-343. [CrossRef]

17. Vacek, L.A.; Rooney, W.L. Effects of cytoplasm, male and female parents on biomass productivity in sorghum (Sorghum bicolor L. Moench). J. Crop Improv. 2018, 32, 635-647. [CrossRef]

18. Boyd, N.S.; Brennan, E.B.; Smith, R.F.; Yokota, R. Effect of seeding rate and planting arrangement on rye cover crop and weed growth. Agron. J. 2009, 101, 47-51. [CrossRef]

19. Smith, S.A.; Popp, M.; Philipp, D. Seedling survival and establishment costs: Crimson and white clover in bermudagrass pastures. Agron. J. 2012, 104, 1517-1522. [CrossRef]

20. Emerson, M.; Carlson, S.; Gailans, S. Aerial Seeding Versus Drill Seeding Cover Crops: Updated with Corn Yield Observations. Field Crops Res. Practical Farmers of Iowa. 2013. Available online: https://practicalfarmers.org/wp-content/ uploads/2018/12/Aerial-seeding-versus-drill-seeding-cover-crops-Updated-with-corn-yield-observations-2013.pdf (accessed on 2 December 2021). 